- 研究报告・

\title{
环境因子对桂西南蚬木林下植被 物种多样性变异的解释
}

\author{
谭一波 $1,2,3$ 申文辉 $1,2,3^{*}$ 付 孜 ${ }^{4}$ 郑 威 $1,2,3$ 欧芷阳 ${ }^{1,2,3}$ 谭长强1,2,3 \\ 彭玉华1,2,3 庞世龙 ${ }^{1,2,3}$ 何琴飞1,2,3 黄小荣 ${ }^{1,2,3}$ 何 峰1,2,3 \\ 1 (广西壮族自治区林业科学研究院, 南宁 530002) \\ 2 (广西优良用材林资源培育重点实验室, 南宁 530002) \\ 3 (广西漓江源森林生态系统国家定位观测研究站, 广西桂林 541316) \\ 4 (广西壮族自治区林业局退耕还林办公室, 南宁 530028)
}

摘要: 探索林下植被分布格局及其影响因素, 对于天然林保护和森林生物多样性维持机制研究具有重要意义。本 文以桂西南喀斯特地区不同蚬木 (Excentrodendron tonkinense) 天然成熟林为研究对象, 采用植物群落样方调查、单 因素方差分析、Pearson相关分析和几余分析(RDA)等方法, 研究了 8 个县市蚬木天然成熟林林下植被物种多样性的 变异及其对土壤、地形和光照等环境因子的响应。结果表明, 林下植被中灌木层优势种主要有越南槐(Sophora tonkinensis)、㧶掌柴(Schefflera heptaphylla)、毛果翼核果(Ventilago calyculata), 以及乔木层幼苗如蚬木、广西澄广 花(Orophea anceps)、岩樟(Cinnamomum saxatile)、金丝李(Garcinia paucinervis)等, 主要来自豆科、五加科、鼠李 科、椴树科、番荔枝科、樟科、藤黄科和大戟科等; 草本层优势种主要有肾藓(Nephrolepis cordifolia)、石山棕(Guihaia argyrata)、崖姜(Pseudodrynaria coronans)、柔枝菍竹(Microstegium vimineum)、水蔗草(Apluda mutica)、沿阶草

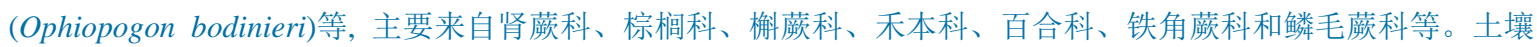
$\mathrm{pH}$ 值、土壤含水量(SWC)、土壤全钾(TK)、土壤全磷( TP) 和坡度(SLO) 是林下植被物种多样性的主要影响因素, 它 们分别解释了林下植被物种多样性 $32.3 \% 、 16.1 \% 、 9.7 \% 、 8.6 \%$ 和 $8.6 \%$ 的变异。灌木丰富度 灌木多样性指数与 TK、 SWC、土壤 $\mathrm{PH}$ 值和 $\mathrm{TP}$ 显著负相关, 而草本丰富度、草本多样性指数则与 TK显著正相关; 灌木密度、灌木盖度与 土壤 $\mathrm{pH}$ 值显著正相关, 草本密度与SWC和TK显著正相关, 草本盖度与 TP、TK显著正相关, 与坡度显著负相关。 土壤和地形因素是影响林下植被物种多样性变异的最主要因素, 而林分冠层结构的影响较小, 土壤各因素对林下 植被物种多样性的影响高于地形因素。

关键词: 冠层结构; 朵余分析(RDA); 土壤养分; 地形因子; 林下植被物种多样性

\section{Effect of environmental factors on understory species diversity in Southwest Guangxi Excentrodendron tonkinense forests}

Yibo Tan ${ }^{1,2,3}$, Wenhui Shen ${ }^{1,2,3^{*}}$, Zi Fu' ${ }^{4}$, Wei Zheng ${ }^{1,2,3}$, Zhiyang Ou ${ }^{1,2,3}$, Zhangqiang Tan $^{1,2,3}$, Yuhua Peng ${ }^{1,2,3}$, Shilong Pang ${ }^{1,2,3}$, Qinfei He $\mathrm{He}^{1,2,3}$, Xiaorong Huang ${ }^{1,2,3}$, Feng $\mathrm{He}^{1,2,3}$

1 Guangxi Zhuang Autonomous Region Forestry Research Institute, Nanning 530002

2 Guangxi Key Laboratory of Superior Timber Trees Resource Cultivation, Nanning 530002

3 Guangxi Lijiangyuan Forest Ecosystem Research Station, Guilin, Guangxi 541316

4 Office of Converting Farmland to Forestry, Guangxi Forestry Bureau, Nanning 530028

Abstract: Exploring how distribution patterns of understory vegetation are affected by environmental factors is of great importance for natural forest protection and biodiversity conservation. Natural and mature Excentrodendron tonkinense-dominated forests on karst terrains were studied in eight counties of Southwest

收稿日期: 2019-04-18; 接受日期: 2019-09-11

基金项目: 广西科技计划项目(桂科AB16380300; 桂科AB1850011)、广西自然科学基金(2017GXNSFAA198102)、广西优良用材林资源培育重点实验 室自主课题(16-A-04-01)和广西林业科技项目(桂林科字[2014]02号)

* 通讯作者 Author for correspondence. E-mail: 769586022@qq.com 
Guangxi. One-way ANOVA, Pearson correlation and redundancy analysis (RDA) were used to investigate the variation in species diversity and understory structure along a gradient of environmental factors including soil, topography, canopy structure and light. The results showed that the shrub layer was dominated by Sophora tonkinensis, Schefflera heptaphylla and Ventilago calyculata, as well as seedlings of species from the tree layer, such as Excentrodendron tonkinense, Orophea anceps, Cinnamomum saxatile and Garcinia paucinervis, etc. These species mainly represented the Leguminosae, Araliaceae, Rhamnaceae, Tiliaceae, Annonaceae, Lauraceae, Guttiferae and Euphorbiaceae families. Within the herb layer, the dominant species were Nephrolepis cordifolia, Guihaia argyrata, Pseudodrynaria coronans, Microstegium vimineum, Apluda mutica and Ophiopogon bodinieri, which mainly represent the Nephrolepidaceae, Palmae, Drynariaceae, Gramineae, Liliaceae, Aspleniaceae and Dryopteridaceae families. Soil pH, soil water content (SWC), soil total potassium (TK), soil total phosphorus (TP) and slope (SLO) were the main influencing factors, respectively explaining the variation in understory species diversity by 32.3\%, 16.1\%, 9.7\%, 8.6\% and 8.6\%. Shrub richness and the shrub diversity index were significantly and negatively correlated with TK, SWC, soil pH and TP, while herb richness and the herb diversity index were significantly and positively correlated with TK. Shrub density and shrub coverage were positively linked to soil $\mathrm{pH}(P<0.05)$, and herb density was positively associated with SWC and TK $(P<0.05)$. Herb coverage was positively correlated with TP and TK, and negatively correlated with slope $(P<0.05)$. Soil and topography were the most important factors affecting species diversity in the understory, while canopy structure had little effect on it. Edaphic factors were found to affect understory species diversity more than topographical factors.

Key words: canopy structure; redundancy analysis; soil nutrients; topographical factors; understory species diversity

林下植被是森林生态系统的重要组成部分，其 物种多样性可直接或间接体现群落稳定性和生境 差异(彭羽等, 2015)。研究林下植被物种多样性的变 异规律及其对环境因子的响应，对物种多样性保护 和植被恢复具有重要意义(盘远方等, 2018)。大量 研 究表明, 林下植被的物种多样性和分布格局受多种 因素影响。在全球或区域尺度上，林下植被分布受 纬度和地带性气候影响(Engler et al, 2009); 在群落 尺度上, 地形、土壤、微生物和林下光环境等微生 境差异及它们之间的协同作用主导着植物的空间 分布(谢玉涁等，2012; 文丽等，2015)。坡度在垂直 方向上影响着水分和土壤养分流向(袁铁象等, 2014)，坡向控制了太阳辐射和降水的再分配(段贝 贝等, 2016)。物种多样性一般随海拔梯度呈多种规 律性变化(刘哲等, 2015; 黄甫昭等, 2016)。土壤养 分则从元素营养方面影响植物的生长和发育(曹建 华等, 2008), 冠层结构和林下光照条件影响森林中 幼苗的更新(Lin et al, 2014; 刘何铭等, 2017)。从影 响程度上看, 不同山地的土壤、地形和冠层结构等 对林下植被物种多样性分布格局具有不同的解释 力，且三者间存在密切的耦合关系。如坡向控制了 地表的光、热、水等环境条件, 能在一定程度上间 接地反映土壤养分的空间差异(余敏等, 2013); 在
海拔梯度较小的范围内，地形因子可能对物种分布 的影响更显著(余敏等，2013); 土壤养分常在环境 因子与群落结构的协同变化中居于主导地位等(欧 芷阳等, 2013b)。

蚬木(Excentrodendron tonkinense) 是广西北热 带喀斯特季节性雨林主要建群种和关键种之一(李 先琨等，2008)，广泛分布于桂西南岩溶山地，与金 丝李(Garcinia paucinervis)、肥牛树(Cephalomappa sinensis)和青冈(Cyclobalanopsis glauca)等组成桂西 南喀斯特山地特有的代表性原生植被，具有维持和 改善生态系统以及保护生物多样性等重要生态功 能(向悟生等, 2013)。由于人为破坏和干扰, 蚬木种 群数量逐渐减少, 已被列入国家二级保护植物名录 (欧芷阳等, 2013b; 向悟生等, 2013)。研究人员对蚬 木种群结构(向悟生等, 2013)、群落动态 ${ }^{1}$ 、幼苗更 新(欧芷阳等，2013a)、群落优势树种与环境因子的 关系(申文辉等, 2017)等方面进行了研究，但对蚬木 林下植被物种多样性及其环境影响因素的研究较 少。影响乔木层的因子是否也同样影响林下植被, 以及土壤理化性质、地形和光等因子对林下植被物 种多样性作用规律的系统解释仍然缺乏，这些都不

(1) 王斌 (2012) 北热带喀斯特季节性雨林蚬木群落生态学研究. 硕士 学位论文, 广西师范大学, 广西桂林. 
利于对喀斯特地区森林植被与岩溶环境之间的相 互作用机制等问题的认识 ${ }^{\circledR}$ 。本文以桂西南喀斯特地 区8 个县市蚬木天然成熟林林下植被为研究对象, 探 讨林下植被物种多样性与环境因子的关系, 揭示影 响林下植被物种多样性的因素及其影响程度, 为合理 地进行生物多样性保护和生态恢复提供理论支撑。

\section{1 材料与方法}

\section{1 研究区概况}

研究区位于广西西南部喀斯特地区, 包括大 新、靖西、龙州、隆安、那坡、平果、天等和武鸣 8 个县市, 地处 $22^{\circ} 9^{\prime}-23^{\circ} 54^{\prime} \mathrm{N}, 105^{\circ} 31^{\prime}-108^{\circ} 37^{\prime} \mathrm{E}$ 之 间。该区域分布着典型的亚热带裸露型岩溶地貌, 气候类型属南亚热带季风性气候, 部分区域属于热 带北缘，具体概况参见申文辉等(2017)。

\section{2 样地设置}

对上述 8 个县市的蚬木天然成熟林群落进行调 查。选择保存相对完好、面积较大且连片的典型蚬 木顶极群落, 在每个群落中各设置 4 个面积为 $20 \mathrm{~m}$ $\times 20 \mathrm{~m}$ 的样地, 共设置32个样地。将每个样地划分 为 4 个 $10 \mathrm{~m} \times 10 \mathrm{~m}$ 的样方, 测定每个样方内胸径大 于 $1 \mathrm{~cm}$ 的立木树高、胸径和冠幅等因子, 记录林龄、 郁闭度、海拔和坡度等群落和环境因子信息。在每 个20 m × $20 \mathrm{~m}$ 样地四角和中部设置 $2 \mathrm{~m} \times 2 \mathrm{~m}$ 小样 方, 调查小样方内灌木和草本的物种组成、数量和 盖度等。不同样地林分特征见表1。

\section{3 土样采集和分析}

在调查样方内按S形线路取0-15 $\mathrm{cm}$ 的表层土 壤10-20处, 混合为约1 kg待测土样带回实验室。测 定土壤因子包括土壤 $\mathrm{pH}$ 值、有机质(soil organic matter, SOM)、土壤含水量(soil water content, SWC)、 全氮(total nitrogen, TN)、全磷(total phosphorus, TP) 和全钾(total potassium, TK) 等6个指标。其中, 土壤 $\mathrm{pH}$ 值采用酸度计法测定, 有机质采用重铬酸钾-外 加热法、土壤含水量采用恒温箱烘干法，全氮采用 半微量凯氏法、全磷采用 $\mathrm{NaOH}$ 熔融-钼锑抗显色紫 外分光光度法、全钾采用 $\mathrm{NaOH}$ 熔融-火焰光度法进 行测定。分析测定方法参照《土壤农化分析》(鲍士 旦, 2000)。

(1) 王斌 (2012) 北热带喀斯特季节性雨林蚬木群落生态学研究. 硕士 学位论文, 广西师范大学, 广西桂林.

\section{4 冠层信息采集和分析}

选择阴天或无风的天气，于日出或日落时间 (区余端和苏志尧等, 2012), 在每个 $20 \mathrm{~m} \times 20 \mathrm{~m}$ 样 地中心和对角线四分位处用松下DMC-LX5数码相 机外接Nikon FC-E8鱼眼镜头共拍摄5张半球面林冠 影像照片。根据样地实际情况, 为避免灌木层干扰, 拍照高度设定在离地面 $1.8 \mathrm{~m}$ 处。采用Gap Light Analyzer (GLA)图像处理软件(Version 2.0)对冠层半 球影像进行分析, 主要指标包括: (1)冠层结构: 林 冠开阔度(canopy openness, CO)和叶面积指数(leaf area index, LAI); (2)林下光环境：林内直射光 (transmitted direct in forest, Trans Dir)、林内散射光 (transmitted diffuse in forest, Trans Dif)、林内总光照 (transmitted total in forest, Trans Tot)和消光系数 (extinction coefficient, $k$ )。这些指标的定义参见谭一 波等(2016)。

\section{5 物种多样性和重要值的计算}

采用样方内物种数目 $S$ 表示物种丰富度。

Shannon-Wiener多样性指数 $\left(H^{\prime}\right)$ 计算公式如下 (马克平和刘玉明, 1994):

$$
H^{\prime}=-\sum_{i}^{S} P_{i} \log _{2} P_{i}
$$

式中, $S$ 为物种数, $P_{i}=n_{i} / N$ 代表第 $i$ 个物种的个体数 $n_{i}$ 占所有个体总数 $N$ 的比例。

重要值(importance value, IV)采用如下公式进 行计算(方精云等, 2009):

乔木IV $(\%)=($ 相对多度 + 相对频度 + 相对 优势度) /3

灌木、草本 $I V(\%)=($ 相对多度 + 相对频度 + 相对盖度) / 3

\section{6 数据分析}

通过野外调查和室内分析，共获得 24 个林下植 被物种多样性指标和微环境因子。包括 8 个林下植 被物种多样性指标: 灌木丰富度、灌木多样性指数、 灌木密度、灌木盖度、草本丰富度、草本多样性指 数、草本密度和草本盖度; 4 个地形因子: 海拔、坡 度、坡位和坡向; 6 个土壤因子: $\mathrm{pH}$ 、有机质、全氮、 全磷、全钾和含水量; 6 个冠层结构和林下光环境因 子: 林冠开阔度、叶面积指数、林内直射光、林内 散射光、林内总光照、消光系数。地形、土壤、冠 层结构和林下光环境因子详见表1和表2。 
表1 桂西南喀斯特地区8个蚬木群落样地林分特征(平均值 \pm 标准误差)

Table 1 Stand characteristics of eight Excentrodendron tonkinense community sampling plots in karst area of Southwest Guangxi (mean $\pm \mathrm{SE})$

\begin{tabular}{llllllll}
\hline $\begin{array}{l}\text { 样地名称 } \\
\text { Sample plots }\end{array}$ & $\begin{array}{l}\text { 纬度 } \\
\text { Latitude }\end{array}$ & $\begin{array}{l}\text { 经度 } \\
\text { Longitude }\end{array}$ & $\begin{array}{l}\text { 海拔 } \\
\text { Altitude }(\mathrm{m})\end{array}$ & $\begin{array}{l}\text { 坡度 } \\
\text { Slope }\end{array}$ & $\begin{array}{l}\text { 坡向指数 } \\
\text { Transformation } \\
\text { of aspect }\end{array}$ & $\begin{array}{l}\text { 平均胸径 } \\
\text { Mean DBH } \\
(\mathrm{cm})\end{array}$ & $\begin{array}{l}\text { 平均树高 } \\
\text { Mean height } \\
(\mathrm{m})\end{array}$ \\
\hline 大新县 Daxin County & $22^{\circ} 49^{\prime} \mathrm{N}$ & $106^{\circ} 46^{\prime} \mathrm{E}$ & 400 & $43^{\circ}$ & 0.97 & $4.93 \pm 0.24$ & $4.72 \pm 0.12$ \\
靖西市 Jingxi City & $22^{\circ} 53^{\prime} \mathrm{N}$ & $106^{\circ} 26^{\prime} \mathrm{E}$ & 357 & $40^{\circ}$ & 0.10 & $4.89 \pm 0.30$ & $5.65 \pm 0.19$ \\
龙州县 Longzhou County & $22^{\circ} 27^{\prime} \mathrm{N}$ & $106^{\circ} 56^{\prime} \mathrm{E}$ & 208 & $46^{\circ}$ & 0.98 & $5.30 \pm 0.36$ & $5.56 \pm 0.19$ \\
隆安县 Longan County & $23^{\circ} 4^{\prime} \mathrm{N}$ & $107^{\circ} 24^{\prime} \mathrm{E}$ & 409 & $42^{\circ}$ & 0.39 & $4.66 \pm 0.29$ & $5.48 \pm 0.24$ \\
那坡县 Napo County & $23^{\circ} 0^{\prime} \mathrm{N}$ & $105^{\circ} 52^{\prime} \mathrm{E}$ & 823 & $23^{\circ}$ & 0.77 & $12.49 \pm 1.73$ & $7.35 \pm 0.52$ \\
平果县 Pingguo County & $23^{\circ} 24^{\prime} \mathrm{N}$ & $107^{\circ} 32^{\prime} \mathrm{E}$ & 350 & $35^{\circ}$ & 0.97 & $3.65 \pm 0.10$ & $3.72 \pm 0.05$ \\
天等县 Tiandeng County & $23^{\circ} 8^{\prime} \mathrm{N}$ & $107^{\circ} 16^{\prime} \mathrm{E}$ & 418 & $40^{\circ}$ & 0.43 & $7.48 \pm 0.53$ & $7.77 \pm 0.25$ \\
武鸣区 Wuming District & $23^{\circ} 16^{\prime} \mathrm{N}$ & $107^{\circ} 51^{\prime} \mathrm{E}$ & 271 & $35^{\circ}$ & 0.98 & $10.34 \pm 0.79$ & $8.38 \pm 0.42$ \\
\hline
\end{tabular}

表2 桂西南喀斯特地区8个蚬木群落样地环境因子汇总(平均值 \pm 标准误差)。同行不同字母表示在不同样地间存在显著差 异 $(P<0.05)$ 。

Table 2 Information on environment factors of eight Excentrodendron tonkinense community sampling plots in karst area of Southwest Guangxi (mean \pm SE). Different letters within the same row meant significant difference among the sampling plots at 0.05 level.

\begin{tabular}{|c|c|c|c|c|c|c|c|c|}
\hline & $\begin{array}{l}\text { 大新县 } \\
\text { Daxin County }\end{array}$ & $\begin{array}{l}\text { 靖西市 } \\
\text { Jingxi City }\end{array}$ & $\begin{array}{l}\text { 龙州县 } \\
\text { Longzhou County }\end{array}$ & $\begin{array}{l}\text { 隆安县 } \\
\text { y Longan County }\end{array}$ & $\begin{array}{l}\text { 那坡县 } \\
\text { Napo County }\end{array}$ & $\begin{array}{l}\text { 平果县 } \\
\text { Pingguo County }\end{array}$ & $\begin{array}{l}\text { 天等县 } \\
\text { Tiandeng County }\end{array}$ & $\begin{array}{l}\text { 武鸣区 } \\
\text { Wuming District }\end{array}$ \\
\hline 土壤帮H Soil pH & $6.66 \pm 0.25^{\mathrm{e}}$ & $7.49 \pm 0.11^{\mathrm{abc}}$ & $7.61 \pm 0.10^{\mathrm{ab}}$ & $7.11 \pm 0.08^{\mathrm{d}}$ & $7.30 \pm 0.02^{\mathrm{bcd}}$ & $6.59 \pm 0.02^{\mathrm{e}}$ & $7.24 \pm 0.09^{\text {cd }}$ & $7.76 \pm 0.02^{\mathrm{a}}$ \\
\hline $\begin{array}{l}\text { 土壤有机质 } \\
\text { Soil organic } \\
\text { matter }(\mathrm{g} / \mathrm{kg})\end{array}$ & $124.17 \pm 18.07^{\mathrm{cd}}$ & $156.42 \pm 21.96^{\mathrm{bc}}$ & $97.15 \pm 7.06^{\mathrm{d}}$ & $144.18 \pm 6.59^{\mathrm{bc}}$ & $369.20 \pm 9.79^{a}$ & $131.96 \pm 10.62^{\mathrm{bcd}}$ & $174.81 \pm 20.34^{b}$ & $172.66 \pm 5.77^{b}$ \\
\hline $\begin{array}{l}\text { 土壤全氮 } \\
\text { Soil total } \\
\text { nitrogen (g/kg) }\end{array}$ & $7.64 \pm 1.02^{b}$ & $8.82 \pm 1.08^{\mathrm{b}}$ & $5.11 \pm 0.26^{c}$ & $6.81 \pm 0.28^{\mathrm{bc}}$ & $22.38 \pm 0.40^{\mathrm{a}}$ & $7.26 \pm 0.63^{b}$ & $8.37 \pm 0.77^{b}$ & $7.75 \pm 0.29^{b}$ \\
\hline $\begin{array}{l}\text { 土壤全磷 } \\
\text { Soil total phosp- } \\
\text { horus (g/kg) }\end{array}$ & $1.75 \pm 0.08^{\mathrm{bc}}$ & $1.88 \pm 0.12^{b}$ & $0.88 \pm 0.05^{\mathrm{ef}}$ & $0.62 \pm 0.03^{f}$ & $6.47 \pm 0.36^{\mathrm{a}}$ & $1.90 \pm 0.07^{\mathrm{b}}$ & $1.26 \pm 0.06^{\mathrm{de}}$ & $1.37 \pm 0.09^{\text {cd }}$ \\
\hline $\begin{array}{l}\text { 土壤全钾 } \\
\text { Soil total pota- } \\
\text { ssium (g/kg) }\end{array}$ & $1.70 \pm 0.24^{\mathrm{d}}$ & $7.81 \pm 0.86^{\mathrm{a}}$ & $2.29 \pm 0.16^{\text {cd }}$ & $3.24 \pm 0.49^{\mathrm{bc}}$ & $3.34 \pm 0.23^{\mathrm{bc}}$ & $3.11 \pm 0.64^{\mathrm{bcd}}$ & $2.38 \pm 0.25^{\mathrm{cd}}$ & $4.37 \pm 0.26^{\mathrm{b}}$ \\
\hline $\begin{array}{l}\text { 土壤C : N } \\
\text { Soil C : N }\end{array}$ & $9.42 \pm 0.34^{c}$ & $10.24 \pm 0.24^{\mathrm{bc}}$ & $11.01 \pm 0.32^{b}$ & $12.27 \pm 0.10^{\mathrm{a}}$ & $9.57 \pm 0.11^{c}$ & $10.55 \pm 0.21^{\mathrm{b}}$ & $12.07 \pm 0.32^{\mathrm{a}}$ & $12.94 \pm 0.47^{\mathrm{a}}$ \\
\hline $\begin{array}{l}\text { 土壤N : P } \\
\text { Soil N : P }\end{array}$ & $4.33 \pm 0.44^{\text {cd }}$ & $4.68 \pm 0.39^{\text {cd }}$ & $5.86 \pm 0.68^{\mathrm{bc}}$ & $11.04 \pm 0.65^{\mathrm{a}}$ & $3.48 \pm 0.13^{\mathrm{d}}$ & $3.85 \pm 0.48^{\mathrm{d}}$ & $6.74 \pm 0.89^{\mathrm{b}}$ & $5.68 \pm 0.16^{\mathrm{bc}}$ \\
\hline $\begin{array}{l}\text { 土壤含水量 } \\
\text { Soil water } \\
\text { content (g/g) }\end{array}$ & $0.40 \pm 0.09^{b}$ & $0.48 \pm 0.06^{\mathrm{b}}$ & $0.35 \pm 0.03^{\mathrm{b}}$ & $0.40 \pm 0.02^{\mathrm{b}}$ & $1.44 \pm 0.06^{\mathrm{a}}$ & $0.41 \pm 0.03^{\mathrm{b}}$ & $0.44 \pm 0.03^{b}$ & $0.47 \pm 0.04^{b}$ \\
\hline $\begin{array}{l}\text { 林冠开阔度 } \\
\text { Canopy } \\
\text { openness (\%) }\end{array}$ & $17.24 \pm 0.41^{\mathrm{a}}$ & $14.20 \pm 0.31^{\mathrm{b}}$ & $13.27 \pm 0.88^{\mathrm{b}}$ & $13.68 \pm 1.42^{b}$ & $15.89 \pm 1.78^{\mathrm{ab}}$ & $13.46 \pm 0.23^{\mathrm{b}}$ & $12.79 \pm 0.54^{\mathrm{b}}$ & $13.83 \pm 0.40^{\mathrm{b}}$ \\
\hline $\begin{array}{l}\text { 叶面积指数 } \\
\text { Leaf area index }\end{array}$ & $2.13 \pm 0.02^{b}$ & $2.40 \pm 0.05^{\mathrm{ab}}$ & $2.50 \pm 0.09^{\mathrm{a}}$ & $2.54 \pm 0.08^{\mathrm{a}}$ & $2.34 \pm 0.26^{\mathrm{ab}}$ & $2.40 \pm 0.08^{\mathrm{ab}}$ & $2.37 \pm 0.02^{\mathrm{ab}}$ & $2.31 \pm 0.07^{\mathrm{ab}}$ \\
\hline $\begin{array}{l}\text { 林内直射光 } \\
\text { Transmitted } \\
\text { direct in forest } \\
\left(\mathrm{mol} \cdot \mathrm{m}^{-2} \cdot \mathrm{d}^{-1}\right)\end{array}$ & $4.42 \pm 0.16^{\mathrm{a}}$ & $3.08 \pm 0.27^{\mathrm{b}}$ & $3.20 \pm 0.33^{b}$ & $2.96 \pm 0.24^{b}$ & $3.28 \pm 0.45^{\mathrm{b}}$ & $3.16 \pm 0.25^{b}$ & $3.47 \pm 0.11^{\mathrm{b}}$ & $3.55 \pm 0.32^{b}$ \\
\hline $\begin{array}{l}\text { 林内散射光 } \\
\text { Transmitted } \\
\text { diffuse in forest } \\
\left(\mathrm{mol} \cdot \mathrm{m}^{-2} \cdot \mathrm{d}^{-1}\right)\end{array}$ & $4.03 \pm 0.05^{\mathrm{a}}$ & $3.35 \pm 0.15^{b}$ & $3.10 \pm 0.13^{b}$ & $2.92 \pm 0.16^{\mathrm{b}}$ & $3.45 \pm 0.43^{b}$ & $3.12 \pm 0.15^{b}$ & $3.17 \pm 0.05^{b}$ & $3.36 \pm 0.13^{b}$ \\
\hline $\begin{array}{l}\text { 林内总光照 } \\
\text { Transmitted } \\
\text { total in forest } \\
\left(\mathrm{mol} \cdot \mathrm{m}^{-2} \cdot \mathrm{d}^{-1}\right)\end{array}$ & $8.45 \pm 0.21^{\mathrm{a}}$ & $6.43 \pm 0.39^{b}$ & $6.30 \pm 0.39^{b}$ & $5.88 \pm 0.34^{b}$ & $6.73 \pm 0.88^{b}$ & $6.28 \pm 0.40^{\mathrm{b}}$ & $6.64 \pm 0.09^{b}$ & $6.91 \pm 0.41^{\mathrm{b}}$ \\
\hline $\begin{array}{l}\text { 消光系数 } \\
\text { Extinction } \\
\text { coefficient (k) }\end{array}$ & $0.72 \pm 0.02^{\mathrm{a}}$ & $0.76 \pm 0.02^{\mathrm{a}}$ & $0.74 \pm 0.03^{\mathrm{a}}$ & $0.75 \pm 0.01^{\mathrm{a}}$ & $0.77 \pm 0.04^{\mathrm{a}}$ & $0.76 \pm 0.01^{\mathrm{a}}$ & $0.75 \pm 0.01^{\mathrm{a}}$ & $0.75 \pm 0.01^{\mathrm{a}}$ \\
\hline
\end{tabular}


采用单因素方差分析(One-Way ANOVA)对不 同样地林下植被物种多样性和微环境因子的差异 进行比较, 采用LSD法进行微环境因子的多重比较, 显著性水平设置为 $P<0.05$; 利用Pearson相关对林 下植被物种多样性指标的相关性进行分析。

采用圥余分析(redundancy analysis, RDA)和多 元线性逐步回归方法分析林下灌木及草本层物种 多样性与环境因子的关系。通过圥余分析前向选择 (forward selection)法和蒙特卡洛检验(Monte Carlo test, 循环次数 499)篮选影响显著 $(P<0.05)$ 的环境 因子, 并分析其解释率。根据调整后的决定系数 (adjusted $R$ square, $R_{\text {adj }}^{2}$ 和假设检验中的 $P$ 值衡量多 元线性回归模型效果, 并得出物种多样性指数与环 境因子的回归关系(盘远方等, 2018)。物种数据采用 林下植被物种多样性指标, 构成 $8 \times 24$ 数据矩阵; 环境变量则构成 $16 \times 24$ 数据矩阵。将罗盘测定的 $0-360^{\circ}$ 之间的方位角转换为 $0-1$ 之间的数值 (transformation of aspect, TRASP)作为坡向, 转换公 式如下:

TRASP $=\{1-\cos [(\pi / 180) \times($ aspect -30$)]\} / 2$ (4) 式中, TRASP为坡向指数, aspect为罗盘所显示的坡 向方位角, TRASP越大, 表示生境越干热(余敏等, 2013)。对样地所在的坡位，用类型变量表示, 1、2、 3分别表示上、中、下坡(邱扬和张金屯, 2000)。为 使数据满足正态分布和方差齐性, 对物种多样性和 环境因子进行对数转换 $\lg (X+1)$ (陈思思和黄秀清, 2018)。

以上所有分析在Canoco 5.0和SPSS 19.0中完成。

\section{2 结果}

\section{1 物种组成}

32 个样方共记录维管束植物 242 种, 隶属 73 科 170属, 重要值排名前4位的优势种见表3。乔木层优 势种主要是蚬木、苹婆(Sterculia monosperma)、岩 樟(Cinnamomum saxatile)、金丝李、广西澄广花(Orophea anceps)、肥牛树、菜豆树(Radermachera sinica)、岩柿(Diospyros dumetorum)、假肥牛树(Cleistanthus petelotii)、清香木(Pistacia weinmannifolia)、 黄荆(Vitex negundo)等。灌木层优势种主要有越南槐 (Sophora tonkinensis)、鹅掌柴(Schefflera heptaphylla)、蚬木、广西澄广花、毛果翼核果(Ventilago calyculata)、亘麻(Boehmeria nivea)、黄荆、岩樟、
金丝李、鱼骨木(Canthium dicoccum)、肥牛树等，主 要来自豆科、五加科、椴树科、番荔枝科、鼠李科、 菖麻科、马鞭草科、樟科、藤黄科、茜草科和大戟 科等。草本层优势种主要有肾硕(Nephrolepis cordifolia)、石山棕(Guihaia argyrata)、崖姜(Pseudodrynaria coronans)、柔枝莠竹(Microstegium vimineum)、水蔗 (Apluda mutica)、蔓生莠竹(Microstegium fasciculatum)、沿阶草(Ophiopogon bodinieri)、狭叶 沿阶草(O. stenophyllus)等，主要来自肾䓲科、棕榈

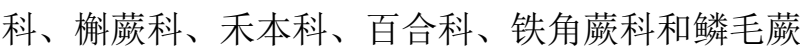
科等喜湿植物。

\section{2 林下植被物种多样性}

方差分析表明(表4), 不同样地间灌木丰富度、 灌木多样性、灌木密度、灌木盖度、草本密度和草 本盖度呈极显著差异, 草本丰富度呈显著差异, 草 本多样性呈不显著差异。由表 5 可以看出, 灌木丰富 度和灌木多样性分别与草本密度和草本盖度极显 著负相关; 草本丰富度与草本多样性和草本盖度极 显著正相关，与草本密度显著正相关。

\section{3 林下植被物种多样性与环境因子的关系}

\subsection{1 林下植被物种多样性与环境因子的几余 分析}

从表6可知, RDA在第一轴和第二轴分别解释 了林下植被物种多样性和环境因子关系变异的 $61.1 \%$ 和 $25.4 \%$, 累积解释量为 $86.5 \%$, 占总可解释 变异的 $94.3 \%$ 。蒙特卡洛检验显示，林下植被物种多 样性和环境因子在第一排序轴和所有排序轴均极 显著相关(表6), 表明RDA排序结果可靠, 能较好地 解释林下植被物种多样性与环境因子间的关系，且 其相关性主要由第一排序轴决定。对林下植被物种 多样性影响显著的环境因子为: 土壤 $\mathrm{pH}$ 值、土壤含 水量、土壤全钾、土壤全磷和坡度(表7)。其中土壤 $\mathrm{pH}$ 值、土壤含水量、土壤全钾和土壤全磷与第一轴 负相关(图1), 分别解释了林下植被多样性 $32.3 \%$ 、 $16.1 \% 、 9.7 \%$ 和 $8.6 \%$ 的变异 $($ 表 7$)$; 坡度与第一轴呈 正相关(图1), 解释率为 $8.6 \%$ 。林分冠层结构和林下 光环境因子没有入选(表7), 说明林分冠层结构和林 下光环境对林下植被物种多样性变异的影响较小。 篮选出的 5 个影响显著的环境因子共解释林下植被 多样性变异的 $75.3 \%$, 虽比全部 16 个环境因子所解 释的信息量少 $16.3 \%$, 但仍较好解释了林下植被物 种多样性变异。 
表3 桂西南喀斯特地区8个蚬木群落样地优势物种组成及其重要值。 $\mathrm{T}$ : 乔木层; $\mathrm{S}$ : 灌木层; H: 草本层。

Table 3 Composition and importance value (IV) of dominant species in eight Excentrodendron tonkinense community sampling plots in karst area of Southwest Guangxi. T, Tree layer; S, Shrub layer; H, Herb layer.

\begin{tabular}{|c|c|c|c|c|c|c|c|}
\hline $\begin{array}{l}\text { 样地 } \\
\text { Plot }\end{array}$ & $\begin{array}{l}\text { 物种 } \\
\text { Species }\end{array}$ & $\begin{array}{l}\text { 层次 } \\
\text { Layer }\end{array}$ & $\begin{array}{l}\text { 重要值 } \\
I V(\%)\end{array}$ & $\begin{array}{l}\text { 样地 } \\
\text { Plot }\end{array}$ & $\begin{array}{l}\text { 物种 } \\
\text { Species }\end{array}$ & $\begin{array}{l}\text { 层次 } \\
\text { Layer }\end{array}$ & $\begin{array}{l}\text { 重要值 } \\
\text { IV (\%) }\end{array}$ \\
\hline \multirow{12}{*}{$\begin{array}{l}\text { 大新县 } \\
\text { Daxin } \\
\text { County }\end{array}$} & 蚬木 Excentrodendron tonkinense & $\mathrm{T}$ & 58.84 & \multirow{12}{*}{$\begin{array}{l}\text { 那坡县 } \\
\text { Napo } \\
\text { County }\end{array}$} & 蚬木 Excentrodendron tonkinense & $\mathrm{T}$ & 33.10 \\
\hline & 广西澄广花 Orophea anceps & $\mathrm{T}$ & 7.29 & & 苹婆 Sterculia monosperma & $\mathrm{T}$ & 8.90 \\
\hline & 岩柿 Diospyros dumetorum & $\mathrm{T}$ & 3.46 & & 樟叶槭 Acer coriaceifolia & $\mathrm{T}$ & 5.59 \\
\hline & 榔榆 Ulmus parvifolia & $\mathrm{T}$ & 3.36 & & 漆 Toxicodendron vernicifluum & $\mathrm{T}$ & 5.41 \\
\hline & 蚬木 Excentrodendron tonkinense & $\mathrm{S}$ & 13.89 & & 我掌柴 Schefflera heptaphylla & S & 26.90 \\
\hline & 红背山麻杆 Alchornea trewioides & $\mathrm{S}$ & 12.52 & & 蚬木 Excentrodendron tonkinense & $\mathrm{S}$ & 19.93 \\
\hline & 光叶紫玉盘 Uvaria boniana & $\mathrm{S}$ & 7.78 & & 香蒲桃 Syzygium odoratum & $\mathrm{S}$ & 5.71 \\
\hline & 鱼骨木 Canthium dicoccum & $\mathrm{S}$ & 6.66 & & 香叶树 Lindera communis & $\mathrm{S}$ & 4.49 \\
\hline & 石山棕 Guihaia argyrata & $\mathrm{H}$ & 27.03 & & 巢硕 Neottopteris nidus & $\mathrm{H}$ & 14.46 \\
\hline & 江南卷柏 Selaginella moellendorffii & $\mathrm{H}$ & 13.09 & & 贯众 Cyrtomium fortunei & $\mathrm{H}$ & 10.34 \\
\hline & 葪蕨 Drynaria roosii & $\mathrm{H}$ & 9.37 & & 肾硕 Nephrolepis cordifolia & $\mathrm{H}$ & 8.77 \\
\hline & 铁角偋 Asplenium trichomanes & $\mathrm{H}$ & 8.92 & & 艾麻 Laportea cuspidata & $\mathrm{H}$ & 8.76 \\
\hline \multirow{12}{*}{$\begin{array}{l}\text { 靖西市 } \\
\text { Jingxi City }\end{array}$} & 蚬木 Excentrodendron tonkinense & $\mathrm{T}$ & 33.69 & \multirow{12}{*}{$\begin{array}{l}\text { 平果县 } \\
\text { Pingguo } \\
\text { County }\end{array}$} & 蚬木 Excentrodendron tonkinense & $\mathrm{T}$ & 11.02 \\
\hline & 岩樟 Cinnamomum saxatile & $\mathrm{T}$ & 17.76 & & 黄荆 Vitex negundo & $\mathrm{T}$ & 8.76 \\
\hline & 苹婆 Sterculia monosperma & $\mathrm{T}$ & 5.18 & & 清香木 Pistacia weinmannifolia & $\mathrm{T}$ & 6.53 \\
\hline & 广西澄广花 Orophea anceps & $\mathrm{T}$ & 1.58 & & 岩柿 Diospyros dumetorum & $\mathrm{T}$ & 5.53 \\
\hline & 亘麻 Boehmeria nivea & $\mathrm{S}$ & 48.41 & & 黄荆 Vitex negundo & S & 21.05 \\
\hline & 岩樟 Cinnamomum saxatile & $\mathrm{S}$ & 18.45 & & 蚬木 Excentrodendron tonkinense & $\mathrm{S}$ & 15.33 \\
\hline & 蚬木 Excentrodendron tonkinense & $\mathrm{S}$ & 13.92 & & 薄皮酒饼簕 Atalantia henryi & $\mathrm{S}$ & 10.25 \\
\hline & 老虎刺 Pterolobium punctatum & $\mathrm{S}$ & 9.99 & & 山石榴 Catunaregam spinosa & $\mathrm{S}$ & 3.68 \\
\hline & 肾蕨 Nephrolepis cordifolia & $\mathrm{H}$ & 11.10 & & 柔枝莠竹 Microstegium vimineum & $\mathrm{H}$ & 50.02 \\
\hline & 蔓生莠竹 Microstegium fasciculatum & $\mathrm{H}$ & 10.26 & & 水蔗草 Apluda mutica & $\mathrm{H}$ & 19.18 \\
\hline & 苦芭菜 Sonchus oleraceus & $\mathrm{H}$ & 5.91 & & 假鞭叶铁线蒴 Adiantum malesianum & $\mathrm{H}$ & 7.75 \\
\hline & 艾麻 Laportea cuspidata & $\mathrm{H}$ & 3.78 & & 硬叶兰 Cymbidium bicolor & $\mathrm{H}$ & 4.87 \\
\hline \multirow{12}{*}{$\begin{array}{l}\text { 龙州县 } \\
\text { Longzhou } \\
\text { County }\end{array}$} & 蚬木 Excentrodendron tonkinense & $\mathrm{T}$ & 25.22 & \multirow{12}{*}{$\begin{array}{l}\text { 天等县 } \\
\text { Tiandeng } \\
\text { County }\end{array}$} & 蚬木 Excentrodendron tonkinense & $\mathrm{T}$ & 43.08 \\
\hline & 广西澄广花 Orophea anceps & $\mathrm{T}$ & 11.38 & & 金丝李 Garcinia paucinervis & $\mathrm{T}$ & 10.74 \\
\hline & 金丝李 Garcinia pauc & $\mathrm{T}$ & 11.28 & & 异叶榕 Ficus heteromorpha & $\mathrm{T}$ & 4.48 \\
\hline & 假肥牛树 Cleistanthus petelotii & $\mathrm{T}$ & 4.23 & & 广西澄广花 Orophea anceps & $\mathrm{T}$ & 4.24 \\
\hline & 广西澄广花 Orophea anceps & $\mathrm{S}$ & 21.26 & & 毛果翼核果 Ventilago calyculata & $\mathrm{S}$ & 17.39 \\
\hline & 九里香 Murraya exotica & $\mathrm{S}$ & 10.89 & & 异叶榕 Ficus heteromorpha & $\mathrm{S}$ & 7.48 \\
\hline & 金丝李 Garcinia paucinervis & $\mathrm{S}$ & 7.29 & & 海红豆 Adenanthera pavonina & S & 7.25 \\
\hline & 牛筋藤 Malaisia scandens & $\mathrm{S}$ & 6.95 & & 金丝李 Garcinia paucinervis & $\mathrm{S}$ & 4.73 \\
\hline & 崖姜 Pseudodrynaria coronans & $\mathrm{H}$ & 9.10 & & 肾蕨 Nephrolepis cordifolia & $\mathrm{H}$ & 20.28 \\
\hline & 鞭叶藃 Cyrtomidictyum lepidocaulon & $\mathrm{H}$ & 5.56 & & 狭叶沿阶草 Ophiopogon stenophyllus & $\mathrm{H}$ & 9.57 \\
\hline & 竹叶草 Oplismenus compositus & $\mathrm{H}$ & 5.31 & & 葪顸 Drynaria roosii & $\mathrm{H}$ & 8.98 \\
\hline & 鞭叶铁线蕨 Adiantum caudatum & $\mathrm{H}$ & 4.37 & & 石韦 Pyrrosia lingua & $\mathrm{H}$ & 8.64 \\
\hline \multirow{12}{*}{$\begin{array}{l}\text { 隆安县 } \\
\text { Longan } \\
\text { County }\end{array}$} & 蚬木 Excentrodendron tonkinense & $\mathrm{T}$ & 46.81 & \multirow{12}{*}{$\begin{array}{l}\text { 武鸣区 } \\
\text { Wuming } \\
\text { District }\end{array}$} & 蚬木 Excentrodendron tonkinense & $\mathrm{T}$ & 69.88 \\
\hline & 九里香 Murraya exotica & $\mathrm{T}$ & 5.98 & & 苹婆 Sterculia monosperma & $\mathrm{T}$ & 8.42 \\
\hline & 肥牛树 Cephalomappa sinensis & $\mathrm{T}$ & 4.65 & & 菜豆树 Radermachera sinica & $\mathrm{T}$ & 5.07 \\
\hline & 青檀 Pteroceltis tatarinowii & $\mathrm{T}$ & 4.58 & & 黄荆 Vitex negundo & $\mathrm{T}$ & 3.29 \\
\hline & 越南槐 Sophora tonkinensis & $\mathrm{S}$ & 23.65 & & 越南槐 Sophora tonkinensis & $\mathrm{S}$ & 34.65 \\
\hline & 九里香 Murraya exotica & $\mathrm{S}$ & 10.05 & & 红背山麻杆 Alchornea trewioides & $\mathrm{S}$ & 18.87 \\
\hline & 肥牛树 Cephalomappa sinensis & $\mathrm{S}$ & 5.55 & & 潺槁木姜子 Litsea glutinosa & S & 5.45 \\
\hline & 红鳞蒲桃 Syzygium hancei & $\mathrm{S}$ & 4.05 & & 黄荆 Vitex negundo & S & 3.47 \\
\hline & 沿阶草 Ophiopogon bodinieri & $\mathrm{H}$ & 47.05 & & 肾蕨 Nephrolepis cordifolia & $\mathrm{H}$ & 48.21 \\
\hline & 褐果臺草 Carex brunnea & $\mathrm{H}$ & 14.07 & & 艾麻 Laportea cuspidata & $\mathrm{H}$ & 6.70 \\
\hline & 肾蕨 Nephrolepis cordifolia & $\mathrm{H}$ & 6.57 & & 鞭叶铁线蕨 Adiantum caudatum & $\mathrm{H}$ & 5.46 \\
\hline & 广西前胡 Peucedanum guangxiense & $\mathrm{H}$ & 4.35 & & 硬叶兰 Cymbidium bicolor & $\mathrm{H}$ & 1.99 \\
\hline
\end{tabular}


表4 桂西南喀斯特地区8个蚬木群落样地林下植被物种多样性方差分析。* $\boldsymbol{P}<\mathbf{0 . 0 5}, * * \boldsymbol{P}<\mathbf{0 . 0 1}$ 。

Table 4 Variance analysis of understory species diversity in eight Excentrodendron tonkinense community sampling plots in karst area of Southwest Guangxi. * $P<0.05, * * P<0.01$.

\begin{tabular}{llll}
\hline 林下植被物种多样性 Understory species diversity & 平方和 Sum of squares & 均方 Mean squares & $F$ \\
\hline 灌木丰富度 Shrub richness (S_shrub) & 502.625 & 71.804 & $4.97^{* *}$ \\
灌木多样性 Shrub diversity (SW_shrub) & 10.455 & 1.494 & $6.08^{* *}$ \\
灌木密度 Shrub density (D_shrub) & $3,728,711.958$ & $532,673.137$ & $11.19^{* *}$ \\
灌木盖度 Shrub coverage (C_shrub) & $2,969.312$ & 424.187 & $4.93^{* * *}$ \\
草本丰富度 Herb richness (S_herb) & 256.000 & 36.571 & $3.46^{*}$ \\
草本多样性 Herb diversity (SW_herb) & 7.880 & 1.126 & 2.46 \\
草本密度 Herb density (D_herb) & $167,753,218.958$ & $23,964,745.565$ & $10.51^{* *}$ \\
草本盖度 Herb coverage (C_herb) & $11,636.273$ & $1,662.325$ & $20.44^{* *}$ \\
\hline
\end{tabular}

表5 桂西南喀斯特地区8个蚬木群落样地林下植被物种多样性指标间的相关系数。* $\boldsymbol{P}<0.05, * * \boldsymbol{P}<0.01$ 。

Table 5 Correlation coefficients of understory species diversity in eight Excentrodendron tonkinense community sampling plots in karst area of Southwest Guangxi. $* P<0.05$, ** $P<0.01$.

\begin{tabular}{|c|c|c|c|c|c|c|c|}
\hline & $\begin{array}{l}\text { 灌木多样性 } \\
\text { Shrub diversity }\end{array}$ & $\begin{array}{l}\text { 灌木密度 } \\
\text { Shrub density }\end{array}$ & $\begin{array}{l}\text { 灌木盖度 } \\
\text { Shrub coverage }\end{array}$ & $\begin{array}{l}\text { 草本丰富度 } \\
\text { Herb richness }\end{array}$ & $\begin{array}{l}\text { 草本多样性 } \\
\text { Herb diversity }\end{array}$ & $\begin{array}{l}\text { 草本密度 } \\
\text { Herb density }\end{array}$ & $\begin{array}{l}\text { 草本盖度 } \\
\text { Herb coverage }\end{array}$ \\
\hline $\begin{array}{l}\text { 灌木丰富度 } \\
\text { Shrub richness }\end{array}$ & $0.867^{* *}$ & 0.063 & 0.297 & -0.327 & -0.268 & $-0.619^{* *}$ & $-0.706^{* *}$ \\
\hline $\begin{array}{l}\text { 灌木多样性 } \\
\text { Shrub diversity }\end{array}$ & & 0.103 & 0.293 & -0.25 & -0.049 & $-0.576^{* *}$ & $-0.660^{* *}$ \\
\hline $\begin{array}{l}\text { 灌木密度 } \\
\text { Shrub density }\end{array}$ & & & $0.738^{* *}$ & -0.314 & -0.111 & -0.076 & -0.205 \\
\hline $\begin{array}{l}\text { 灌木盖度 } \\
\text { Shrub coverage }\end{array}$ & & & & -0.350 & -0.171 & 0.05 & -0.169 \\
\hline $\begin{array}{l}\text { 草本丰富度 } \\
\text { Herb richness }\end{array}$ & & & & & $0.783^{* *}$ & $0.431^{*}$ & $0.634^{* *}$ \\
\hline $\begin{array}{l}\text { 草本多样性 } \\
\text { Herb diversity }\end{array}$ & & & & & & 0.275 & $0.430^{*}$ \\
\hline $\begin{array}{l}\text { 草本密度 } \\
\text { Herb density }\end{array}$ & & & & & & & $0.861^{* *}$ \\
\hline
\end{tabular}

\section{表6 林下植被物种多样性与环境因子的罙余分析(RDA)排序}

Table 6 Summary of redundancy analysis (RDA) ordination of understory species diversity and environmental factors

\begin{tabular}{|c|c|c|c|c|c|}
\hline $\begin{array}{l}\text { 排序概要 } \\
\text { Summary of ordination }\end{array}$ & $\begin{array}{l}\text { 第1轴 } \\
\text { Axis } 1\end{array}$ & $\begin{array}{l}\text { 第2轴 } \\
\text { Axis } 2\end{array}$ & $\begin{array}{l}\text { 第3轴 } \\
\text { Axis } 3\end{array}$ & $\begin{array}{l}\text { 第4轴 } \\
\text { Axis } 4\end{array}$ & $\begin{array}{l}\text { 总方差 } \\
\text { Total variance }\end{array}$ \\
\hline 特征值 Eigenvalues & 0.611 & 0.254 & 0.035 & 0.017 & 1 \\
\hline $\begin{array}{l}\text { 林下植被物种多样性-环境因子相关 } \\
\text { Understory species diversity-environmental factors correlations }\end{array}$ & 0.980 & 0.969 & 0.886 & 0.892 & \\
\hline $\begin{array}{l}\text { 解释的林下植被物种多样性组成变异的累积百分比 } \\
\text { Cumulative percentage variance of understory species diversity data (\%) }\end{array}$ & 61.1 & 86.5 & 90.0 & 91.7 & \\
\hline $\begin{array}{l}\text { 林下植被物种多样性-环境因子关系方差的累积百分比 } \\
\text { Cumulative percentage variance of understory species } \\
\text { diversity-environmental factors relation (\%) }\end{array}$ & 65.3 & 92.5 & 96.2 & 98.1 & \\
\hline 特征值总和 Sum of eigenvalues & & & & & 1 \\
\hline 典型特征值总和 Sum of canonical eigenvalues & & & & & 0.935 \\
\hline 第一典范轴的显著性测验 Significant test of the first canonical axis & \multicolumn{5}{|c|}{$F=10.975, P=0.002$} \\
\hline 所有典范轴的显著性测验 Significant test of all canonical axes & \multicolumn{5}{|c|}{$F=6.248, P=0.002$} \\
\hline
\end{tabular}


表7 冗余分析(RDA)中环境因子对林下植被物种多样性的 解释率。* $P<0.05, * * P<0.01$ 。

Table 7 Contribution of significant environmental factors affecting understory species diversity in redundancy analysis (RDA). $* P<0.05$, ** $P<0.01$.

\begin{tabular}{lll}
\hline 环境因子 Environmental factors & \multicolumn{2}{c}{ 解释率 } \\
Contribution (\%) \\
\hline 土壤pH Soil pH & 32.3 & $9.4^{* *}$ \\
土壤含水量 Soil water content (SWC) & 16.1 & $6.0^{* *}$ \\
土壤全钾 Soil total potassium (TK) & 9.7 & $4.7^{* *}$ \\
土壤全磷 Soil total phosphorus (TP) & 8.6 & $4.9^{* *}$ \\
坡度 Slope (SLO) & 8.6 & $3.4^{*}$ \\
海拔 Elevation (ELE) & 3.6 & 2.2 \\
土壤有机质 Soil organic matter (SOM) & 3.6 & 2.2 \\
林内散射光 Transmitted diffuse in forest (Trans Dif) 3.1 & 1.9 \\
林冠开阔度 Canopy openness (CO) & 2.5 & 1.5 \\
坡向 Slope aspect (SLOA) & 2.4 & 1.4 \\
林内总光照 Transmitted total in forest (Trans Tot) & 2.3 & 1.3 \\
土壤全氮 Soil total nitrogen (TN) & 2 & 1.2 \\
林内直射光 Transmitted direct in forest (Trans Dir) & 1.6 & 0.9 \\
坡位 Slope position & 1.5 & 0.8 \\
叶面积指数 Leaf area index (LAI) & 1 & 0.5 \\
消光系数 Extinction coefficient ( $k$ ) & 0.6 & 0.3 \\
\hline
\end{tabular}

\subsection{2 林下植被物种多样性与环境因子的逐步回} 归分析

结合表 8 和图1可知, 灌木丰富度与土壤全钾、 土壤含水量和土壤 $\mathrm{pH}$ 值显著负相关, 灌木多样性 与土壤全钾、土壤全磷显著负相关, 而灌木密度和 灌木盖度与土壤pH显著正相关。草本丰富度、草本 多样性、草本密度和草本盖度均与土壤全钾显著正 相关，其中草本密度还与土壤含水量显著正相关， 草本盖度与土壤全磷显著正相关, 与坡度显著负相

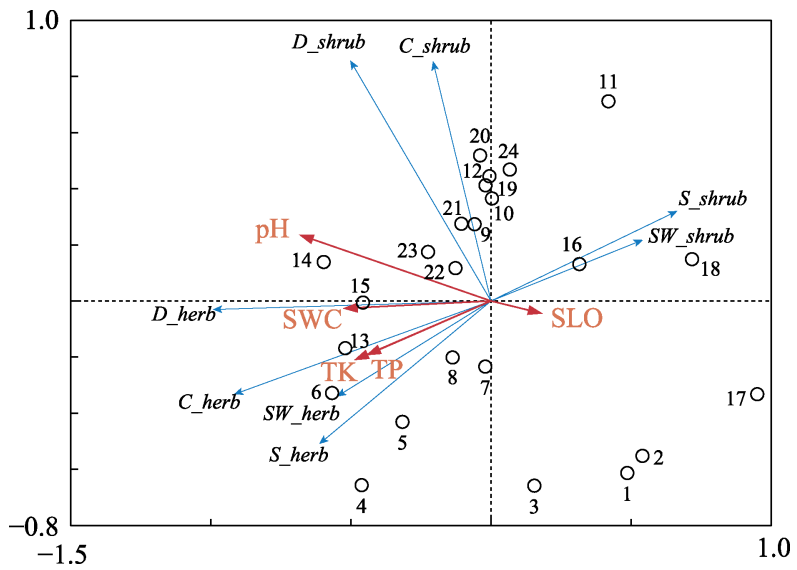

图1 林下植被物种多样性和环境因子的RDA排序图。图中 阿拉伯数字代表 24 个样地; 红色箭头线段表示环境因子(仅 显示具有显著影响的因子, $P<0.05)$, 蓝色箭头表示林下植 物多样性因子。 pH、SWC、SLO、TK、TP、SW_shrub、 D_shrub、C_shrub、S_herb、SW_herb、D_herb和C_herb 含义见表4和表7。

Fig. 1 RDA ordination diagram of understory species diversity and environmental factors. The arabic numerals in the figure represent 24 sample plots. The red arrow lines represent environmental factors (the factors with significant effects are display only, $P<0.05$ ). The blue arrows lines represent diversity factors of understory plants. $\mathrm{pH}$, SWC, SLO, TK, TP, SW_shrub, D_shrub, C_shrub, S_herb, SW_herb, D_herb and C_herb are the same as in Table 4 and Table 7.

关。从模型调整决定系数 $R_{\mathrm{adj}}^{2}$ 看, 土壤 $\mathrm{pH}$ 值对灌木 密度, 土壤全钾对草本丰富度的解释率较低。

\section{3 讨论}

许多研究表明，在群落等小尺度上，地形、土 壤和林下光环境等微生境因子是调控林下植被组 成和分布的重要因素(Siefert et al, 2012; 余敏等, 2013; 尤业明等, 2018)。本研究显示, 土壤因子中的

表8＼cjkstart林下植被物种多样性与环境因子的逐步回归分析。SWC、SLO、TK和TP含义见表7。

Table 8 Stepwise regression analysis of understory species diversity and environmental factors. SWC, SLO, TK and TP are the same as in Table 7.

\begin{tabular}{llll}
\hline 林下植被物种多样性 & 逐步回归方程 & 调整后决定系数 & $P$ \\
Understory species diversity & Stepwise regression equation & Adjusted $R$ square $\left(R_{\mathrm{adj}}^{2}\right)$ \\
\hline 灌木丰富度 Shrub richness (S_shrub) & S_shrub $=57.560-1.184 \mathrm{TK}-6.416$ SWC $-5.410 \mathrm{pH}$ & 0.599 & 0.015 \\
灌木多样性 Shrub diversity (SW_shrub) & SW_shrub $=3.938-0.290 \mathrm{TK}-0.173 \mathrm{TP}$ & 0.661 & 0.004 \\
灌木密度 Shrub density (D_shrub) & D_shrub $=-2888.420+482.654 \mathrm{pH}$ & 0.189 & 0.019 \\
灌木盖度 Shrub coverage (C_shrub) & C_shrub $=5.855+0.023 \mathrm{D} \_s h r u b$ & 0.524 & $<0.001$ \\
草本丰富度 Herb richness (S_herb) & S_herb $=4.752+1.156 \mathrm{TK}$ & 0.239 & 0.009 \\
草本多样性 Herb diversity (SW_herb) & SW_herb $=0.849+0.148 S \_h e r b$ & 0.595 & $<0.001$ \\
草本密度 Herb density (D_herb) & D_herb $=-3061.719+6073.551 S W C+579.980 T K$ & 0.663 & 0.005 \\
草本盖度 Herb coverage (C_herb) & C_herb $=-90.729+7.579 T K+12.862 T P-1.653 S L O$ & 0.725 & 0.007 \\
\hline
\end{tabular}


$\mathrm{pH}$ 值、土壤含水量、土壤全钾、土壤全磷和地形因 子中的坡度是影响林下植被物种多样性变异的最 主要因素, 林分冠层结构和林下光环境的影响较小, 且土壤各因素效应高于地形因素(表7)。

\section{1 土壤 $\mathrm{pH}$ 值}

土壤 $\mathrm{pH}$ 值表征土壤酸碱程度。一方面, 喀斯特 地区碳酸盐中钙的大量迁移使土壤偏碱性(李先琨 等, 2008)，抑制了部分植物的生长(文丽等，2015); 另一方面，植被的正向演替提高了土壤有机质含量, 降低了 $\mathrm{pH}$ 值, 有利于植物定居和发展(Sohlberg \& Bliss, 1984)。上述两个过程对植物的分布具有重要 影响。本研究发现, 灌木密度与 $\mathrm{pH}$ 值显著正相关(表 8), 相应样地的坡度较小，同时灌木盖度也较大， 但灌木丰富度和多样性较小, 说明在土壤 $\mathrm{pH}$ 值较 高、土壤养分和水分较好的缓坡地段, 我掌柴、越 南槐、蚬木幼苗、光叶紫玉盘(Uvaria boniana)、毛 果翼核果等灌木优势种通过对 $\mathrm{pH}$ 值较高的碱性土 壤的适应, 能与草本植物共同占据生境较好的地 段。本研究中, 草本植物多样性和丰富度与土壤 $\mathrm{pH}$ 值正相关，但灌木多样性和丰富度则相反。喀斯特 山地雨水冲刷和淋溶作用使坡度较小地段的土壤 $\mathrm{pH}$ 值呈碱性(表2和图1)。通常, 林下植被的生长受 到必需土壤营养元素的有效性、有毒元素的溶解性 和土壤微生物群落的影响(Weaver \& Hamill, 1985)。

对于灌木或者乔木更新层来说, 较高的 $\mathrm{pH}$ 值 和土壤含水量能够降低土壤营养元素有效性(如有 效磷), 增加有毒元素的溶解, 抑制土壤微生物和一 些不耐碱及对有毒元素敏感的灌木植物的生长。此 外, 较高的 $\mathrm{pH}$ 值对部分灌木或者乔木种子萌发具 有抑制作用, 从而降低了灌木层物种丰富度(Ma et al, 2012)。而喜湿的草本钙生植物如石山棕、江南 卷柏(Selaginella moellendorffii)、鞭叶蕨(Cyrtomidictyum lepidocaulon)、广西前胡(Peucedanum guangxiense)、贯众(Cyrtomium fortunei)和鞭叶铁线蒝 (Adiantum caudatum)等, 对较高的土壤 $\mathrm{pH}$ 值有一定 的耐受性, 且坡度较小的湿润环境也有利于其生 长。我们还发现, 大新县样地土壤偏酸性, 其灌木 层多样性均较其他样地高。究其原因, 较强的林下 光照增强了调落物分解和土壤有机质累积, 降低了 土壤 $\mathrm{pH}$ 值, 提供了更多植物定居的可能。综上, 土 壤 $\mathrm{pH}$ 值作为林下植被物种多样性的首要限制因子 (表7), 提示我们在次生林向原生林演替过程中, 保
证合理的土壤酸碱度(杜虎等，2013)能够促进林下 灌木层植物的快速发展。

\section{2 土壤水分}

多数研究表明植物群落生长及多样性分布与 土壤水分条件密切相关(郝文芳等, 2012)。本研究中 土壤含水量是限制灌木和草本群落物种多样性的 主要环境因子(表7和图1), 灌木丰富度与土壤含水 量显著负相关(表8), 草本密度与土壤含水量极显著 正相关(表8)。如土壤含水量最大、坡度最小的那坡 县样地(表1和表2), 每个 $400 \mathrm{~m}^{2}$ 样地灌木仅有3-6种, 草本密度则达到 $5,000-12,000$ 株。而坡度最大、土 壤含水量最小的龙州县样地, 每个 $400 \mathrm{~m}^{2}$ 样地灌木 种类提高到7-14种, 草本密度则降到600-1,000株。

一般来说, 坡度较小的喀斯特山地通常土层较厚, 土壤含水量、 $\mathrm{pH}$ 值和养分含量相对较高, 利于耐碱 性的草本植物生长和形成竞争优势。同时, 从灌木 丰富度和灌木多样性分别与草本密度和草本盖度 极显著负相关(表5)可以看出, 灌木植物可能因草本 密度大，在种子萌发、养分和水分竞争中处于劣势; 虽有部分单优灌木(如鹅掌柴、越南槐、蚬木幼苗等) 的存在, 但灌木丰富度和多样性大大降低。有研究 认为, 喀斯特地区土壤含水量不是限制乔木层物种 多样性发展的主要因子(欧芷阳等, 2014), 是因为乔 木植物具有庞大的根系，可充分利用不同深度裂隙 水(聂云鹏等, 2011)和地下岩溶表层带的水分及养 分(何成新等, 2007)。相反, 本研究中林下植被存在 较多浅根系植物(如越南槐、毛果翼核果、兌麻、红 背山麻杆(Alchornea trewioides)和草本植物等), 更 多依赖于表层土壤水分和浅层裂隙水(聂云鹏等, 2011), 而表层土壤含水量则可能通过影响养分的 可利用性、有毒元素的溶解和土壤 $\mathrm{pH}$ 值来影响植物 分布(Ma et al，2017)和物种多样性(Hájek et al, 2013)。我掌柴等单优灌木较大的竞争优势与对深层 裂隙水较强的利用能力(聂云鹏等, 2011)以及植物 自身生理生态学特性密切相关。

\section{3 土壤养分}

土壤养分是驱动小尺度植被物种分布格局的 重要因子(Siefert et al, 2012; 尤业明等, 2018), 且其 对植物物种多样性的影响较为复杂, 没有表现出一 致的规律性(宁志英等, 2019)。本研究中, 灌木和草 本植物的多样性均与土壤全钾或全磷显著相关，与 前人研究认为喀斯特森林中全磷、全钾是木本植物 
分布及物种多样性的重要驱动因子(Zhang et al, 2013; 欧芷阳等, 2014; 申文辉等, 2017)的结论相似, 但土壤全钾对草本丰富度的解释率较低(表8)。

本研究样地土壤全磷含量均值为 $2.02 \mathrm{~g} / \mathrm{kg}$, 与 广西岩溶山地原生林土壤全磷含量均值 $1.86 \mathrm{~g} / \mathrm{kg}$ (蒋忠诚等, 2011)接近, 但远高于中国表层土壤全磷 含量均值 $0.78 \mathrm{~g} / \mathrm{kg}$ (Tian et al, 2010), 以及浙江天童 木荷(Schima superba)林 $0.89 \mathrm{~g} / \mathrm{kg}$ (王希华, 2010)、湖 南会同常绿润叶林 $0.19 \mathrm{~g} / \mathrm{kg}$ (汪思龙, 2012)和广东 鹤山乡土林 $0.21 \mathrm{~g} / \mathrm{kg}$ (傅声雷等, 2011)等土壤全磷 含量均值。可以看出尽管土壤全磷的含量不低, 但 磷却成为灌木层物种多样性的限制因子, 这可能是 因为在坡度较小区域, 较高的水分、 $\mathrm{Ca}^{2+}$ 含量和 $\mathrm{pH}$ 值增强了土壤的固磷作用, 形成难溶的磷灰石, 导 致磷的有效性降低(廖菁菁等, 2007); 而岩石母质 层、调落物等淋溶出的P元素主要向坡底等区域汇 集，造成坡度大的区域土壤中 $\mathrm{P}$ 元素减少。研究表明， 植物沿土壤养分资源梯度的生态位分化被认为是 森林群落中植物共存的潜在机制之一 (Steidinger, 2015; 徐远杰等, 2017), Steidinger (2015)对193个树 种生态位宽度的研究认为, 树种针对土壤磷和钙的 生态位分化只发生在磷和钙含量较低的情况下。本 研究中, 在磷和钻含量较低的大坡度区域, 发生灌 木植物对土壤磷和钙的专化利用, 形成生态位分化, 是对灌木丰富度增加的一种可能解释。

本研究中, 土壤全钾含量均值为 $3.53 \mathrm{~g} / \mathrm{kg}$, 低 于广西岩溶山地原生林土壤全钾含量均值 $4.90 \mathrm{~g} / \mathrm{kg}$ (蒋忠诚等, 2011), 更远低于中国南方典型常绿阔叶 林土壤全钾含量均值31.85 g/kg (王希华, 2010; 傅 声雷等, 2011; 汪思龙, 2012), 与谭宏伟等(2006)研 究认为在广西亚热带岩溶地区钾素是主要养分限 制因子的结论相似。一般来说, 过量的土壤钾含量 会降低群落水平的细根生物量(Wright et al, 2011; 徐远杰等, 2017), 而在坡度较小的地段, 钾通过淋 溶和植物表聚作用，其含量高于大坡度区域，容易 造成灌木损伤进而降低其丰富度。而草本植物并未 受土壤钾含量增加的伤害, 草本丰富度与土壤全钾 仍呈显著正相关, 但解释率较低, 其原因尚待深入 研究。

桂西南蚬木样地土壤全氮含量均值为 $9.27 \mathrm{~g} / \mathrm{kg}$, 较桂西南弄岗喀斯特森林 $(7.05 \mathrm{~g} / \mathrm{kg}$, 郭屹立等, 2017)和桂西北喀斯特顶极群落(4.83 g/kg, 彭晚霞,
2009)要高, 远高于第二次全国土壤普查中全国非 耕地土壤氮含量 $1.43 \mathrm{~g} / \mathrm{kg}$ (吕贻忠和李保国, 2006), 其土壤N : P均值(5.70, 表2)与中国热带亚热带土壤 (6.40, 白坤栋等, 2015)接近, 表明桂西南蚬木林样 地土壤氮不受限制, 与本研究中土壤全氮(表7)对林 下植被物种多样性较低的解释率相应证, 也与一般 认为湿润热带亚热带地区生态系统氮素相对富集, 土壤氮是饱和的研究结论相同(Hall \& Matson, 1999; Matson et al, 2002)。

\section{4 坡度}

坡度作为影响林下植被物种多样性变异的主 要地形因子, 解释了林下植被物种多样性 $8.6 \%$ 的变 异，与袁铁象等(2014)对桂西南喀斯特山地森林灌 木、草本植物多样性的研究结果相似。坡度在垂直 方向上影响着水分和土壤养分流向，图1第一轴环 境因子的排序较好反映了这样的关系。袁铁象等 (2014)研究中桂西南喀斯特山地坡度对土壤水分、 养分的作用强于海拔等地形因子, 本研究也有同样 的发现，且随着坡度的增加，土壤厚度、养分和含 水量逐渐降低, 导致最终土壤因子成为限制林下植 被物种多样性的主要因素。灌木物种丰富度、多样 性与土壤全钾、土壤含水量、土壤 $\mathrm{pH}$ 值和土壤全磷 显著负相关(表8), 同时灌木物种丰富度、多样性高 的样地主要分布在坡度较大的区域(图1)。这与一般 认为土壤磷、钾、有机质等含量中等或较低时植物 物种丰富度较高(Potts et al, 2002)的结论相似。随坡 度增加，喀斯特异质性生境增加，同时土壤养分和 水分条件更加严酷, 较少物种在大坡度区域形成绝 对优势，从而支持更多物种在该区域共存(黄甫昭 等, 2016)。

\section{5 海拔、坡向和光照}

本研究中, 样地间海拔差异较小, 海拔对水、 热资源分布的影响不显著(表7)。坡向作为一种重要 的地形因素，控制了太阳辐射和降水的空间再分配， 进而影响植物群落物种多样性(段贝贝等, 2016)。由 于蚬木成熟林分被当地村民视为风水林或者位于 自然保护区，均得到较好的保护，林分郁闭度较高， 乔木层冠层结构和林下光环境大部分差异不显著 (表2), 因此由坡向引起的太阳辐射和降水变化对林 下植被的影响作用被削弱，与申文辉等(2016)对该 地区蚬木群落调查结果相似。许多研究认为, 光照 是林下植被生长的主要限制因素之一(陈志刚等, 
2005; 卢训令等, 2013), 特别是在人工林中(尤业明 等, 2018)。通过RDA前向选择的笁选结果表明, 蚬 木成熟林林下植被物种多样性与冠层结构特征间 相关性不显著，林分冠层结构和林下光环境对林下 植被物种多样性变异的影响较小。与Gracia等(2007) 认为天然林冠层结构因素的作用不如立地条件重 要, 土壤、地形和边缘效应等对林下植被组成的累 积驱动效应更为重要(余敏等, 2013)的结论相似。

\section{参考文献}

Bai KD, Mo L, Liu M, Zhang DN, He CX, Wan XC, Jiang DB (2015) Nutrient resorption patterns of evergreen and deciduous tree species at different altitudes on Mao'er Mountain, Guangxi. Acta Ecologica Sinica, 35, 5776-5787. (in Chinese with English abstract) [白坤栋, 莫凌, 刘铭, 张德楠, 何成新, 万贤崇, 蒋得斌 (2015) 广西猫儿山不同海拔常 绿和落叶树种的营养再吸收模式. 生态学报, 35, 5776-5787.]

Bao SD (2000) Soil Agro-Chemistrical Analysis. China Agriculture Press, Beijing. (in Chinese) [鲍士旦 (2000) 土壤农 化分析. 中国农业出版社, 北京.]

Cao JH, Jiang ZC, Yang DS, Pei JG, Yang H, Luo WQ (2008) Grading of soil erosion intensity in Southwest karst area of China. Science of Soil and Water Conservation, 6(6), 1-7, 20. (in Chinese with English abstract) [曹建华, 蒋忠诚, 杨 德生, 裴建国, 杨慧, 罗为群 (2008) 我国西南岩溶区土 壤侵蚀强度分级标准研究. 中国水土保持科学, 6(6), 1-7, 20.]

Chen SS, Huang XQ (2018) Plant functional traits and the factors influencing them in the islands of eastern China. Acta Ecologica Sinica, 38, 7699-7707. (in Chinese with English abstract) [陈思思, 黄秀清 (2018) 中国东部海岛 植物功能性状及其影响因子. 生态学报, 38, 7699-7707.]

Chen ZG, Fan DY, Zhang WF, Xie ZQ (2005) Effects of gap and understory environments on the regeneration of Quercus aliena var. acuteserrata and Fagus engleriana. Acta Phytoecologica Sinica, 29, 354-360. (in Chinese with English abstract) [陈志刚, 樊大勇, 张旺锋, 谢宗强 (2005) 林隙 与林下环境对锐齿䚞柇和米心水青冈种群更新的影响. 植物生态学报, 29, 354-360.]

Duan BB, Zhao CZ, Xu T, Zheng HL, Feng W, Han L (2016) Correlation analysis between vein density and stomatal traits of Robinia pseudoacacia in different aspects of Beishan Mountain in Lanzhou. Chinese Journal of Plant Ecology, 40, 1289-1297. (in Chinese with English abstract) [段贝贝, 赵 成章, 徐婷, 郑慧玲, 冯威, 韩玲 (2016) 兰州北山不同 坡向刺槐叶脉密度与气孔性状的关联性分析. 植物生态 学报, 40, 1289-1297.]

Du H, Peng WX, Song TQ, Wang KL, Zeng FP, Lu SY, Shi WW, Tang C, Tan QJ (2013) Plant community characteristics and its coupling relationships with soil in depressions between karst hills, North Guangxi, China. Chinese Journal of Plant Ecology, 37, 197-208. (in Chinese with English abstract) [杜虎, 彭晚霞, 宋同清, 王克林, 曾馥平, 鹿士 杨, 时伟伟, 唐成, 谭秋锦 (2013) 桂北喀斯特峰从洼地 植物群落特征及其与土壤的耦合关系. 植物生态学报, 37, 197-208.]

Engler R, Randin CF, Vittoz P, Czáka T, Beniston M, Zimmermann NE, Guisan A (2009) Predicting future distributions of mountain plants under climate change: Does dispersal capacity matter? Ecography, 32, 34-45.

Fang JY, Wang XP, Shen ZH, Tang ZY, He JS, Yu D, Jiang Y, Wang ZH, Zheng CY, Zhu JL, Guo ZD (2009) Methods and protocols for plant community inventory. Biodiversity Science, 17, 533-548. (in Chinese with English abstract) [方精 云，王襄平，沈泽昊，唐志尧，贺金生，于丹，江源，王志 恒, 郑成洋, 朱江玲, 郭兆迪 (2009) 植物群落清查的主 要内容、方法和技术规范. 生物多样性, 17, 533-548.]

Fu SL, Lin YB, Rao XQ, Liu SP (2011) The Dataset of Observation and Research on Chinese Ecosystem: Forest Ecosystem of Heshan Station, Guangdong Province (1998-2008). China Agriculture Press, Beijing. (in Chinese) [傅声雷, 林 永标, 饶兴权, 刘素萍 (2011) 中国生态系统定位观测与 研究数据集: 森林生态系统卷(广东鹤山站1998-2008). 中国农业出版社, 北京.]

Gracia M, Montané F, Piqué J, Retana J (2007) Overstory structure and topographic gradients determining diversity and abundance of understory shrub species in temperate forests in central Pyrenees (NE Spain). Forest Ecology and Management, 242, 391-397.

Guo YL, Li DX, Wang B, Bai KD, Xiang WS, Li XK (2017) $\mathrm{C}, \mathrm{N}$ and $\mathrm{P}$ stoichiometric characteristics of soil and litter fall for six common tree species in a northern tropical karst seasonal rainforest in Nonggang, Guangxi, southern China. Biodiversity Science, 25, 1085-1094. (in Chinese with English abstract) [郭屹立, 李冬兴, 王斌, 白坤栋, 向悟 生, 李先琨 (2017) 北热带喀斯特季节性雨林土壤和6个 常见树种调落物的C、N、P化学计量学特征. 生物多样性, 25, 1085-1094.]

Hájek M, Hájková $P$, Kočí M, Jiroušek M, Mikulášková E, Kintrová K (2013) Do we need soil moisture measurements in the vegetation-environment studies in wetlands? Journal of Vegetation Science, 24, 127-137.

Hall SJ, Matson PA (1999) Nitrogen oxide emissions after nitrogen additions in tropical forests. Nature, 400, 152-155.

Hao WF, Du F, Chen XY, Liang ZS (2012) Composition and diversity analysis of natural-community plants in the Loess Hilly Region. Acta Agrestia Sinica, 20, 609-615. (in Chinese with English abstract) [郝文芳, 杜峰, 陈小燕, 梁 宗锁 (2012) 黄土丘陵区天然群落的植物组成、植物多样 性及其与环境因子的关系. 草地学报, 20, 609-615.]

He CX, Huang YQ, Li XK, Wang XY, Wang Q (2007) The ecophysiological traits of three karst rockey desert restoration species. Guihaia, 27, 53-61. (in Chinese with English 
abstract) [何成新, 黄玉清, 李先琨, 王晓英, 汪青 (2007) 岩溶石漠化地区几种生态恢复植物的生理生态学特征. 广西植物, 27, 53-61.)

Huang FZ, Ding T, Li XK, Guo YL, Wang B, Xiang WS, Wen SJ, Li DX, He YL (2016) Species diversity for various associations along an altitudinal gradient in the karst seasonal rainforest in Nonggang. Acta Ecologica Sinica, 36, 4509-4517. (in Chinese with English abstract) [黄甫昭, 丁 涛, 李先琨, 郭屹立, 王斌, 向悟生, 文淑均, 李冬兴, 何 运林 (2016) 弄岗喀斯特季节性雨林不同群丛物种多样 性随海拔的变化. 生态学报, 36, 4509-4517.]

Jiang ZC, Li XK, Hu BQ (2011) Rocky Desertification and Its Comprehensive Management in Karst Mountain Areas of Guangxi. Science Press, Beijing. (in Chinese) [蒋忠诚, 李 先琨, 胡宝清 (2011) 广西岩溶山区石漠化及其综合治 理研究. 科学出版社, 北京.]

Liao JJ, Huang B, Sun WX, Zou Z, Su JP, Ding F, Huang Y (2007) Spatio-temporal variation of soil available phosphorus and its influencing factors-A case study of Rugao County, Jiangsu Province. Acta Pedologica Sinica, 44, 620-628. (in Chinese with English abstract) [廖菁菁, 黄标, 孙维侠, 邹忠, 苏建平, 丁峰, 黄耀 (2007) 农田土壤有效磷的时 空变异及其影响因素分析- - 以江苏省如臬市为例. 土 壤学报, 44, 620-628.]

Li XK, Jiang ZC, Huang YQ, Xiang WS, Lü SH, Ye D, Su ZM (2008) Dynamics of dominant population and its influence on karstifikation in Southwest Guangxi, China. Acta Geoscientica Sinica, 29, 253-259. (in Chinese with English abstract) [李先琨, 蒋忠诚, 黄玉清, 向悟生, 吕仕洪, 叶 铎, 苏宗明 (2008) 桂西南岩溶山地优势植物种群动态 及其对岩溶作用的影响. 地球学报, 29, 253-259.]

Lin F, Comita LS, Wang XG, Bai XJ, Yuan ZQ, Xing DL, Hao ZQ (2014) The contribution of understory light availability and biotic neighborhood to seedling survival in secondary versus old-growth temperate forest. Plant Ecology, 215, 795-807.

Liu HM, Ma ZP, Yang QS, Fang XF, Lin QK, Zong Y, Aqing A, Wang XH (2017) Relationships between established seedling survival and growth in evergreen broad-leaved forest in Tiantong. Biodiversity Science, 25, 11-22. (in Chinese with English abstract) [刘何铭, 马遵平, 杨庆松, 方晓峰, 林庆凯, 宗意, 阿尔达克·阿庆, 王希华 (2017) 天童常绿阔叶林定居幼苗存活和生长的关联. 生物多样 性, 25, 11-22.]

Liu Z, Li Q, Chen DD, Zhai WT, Zhao L, Xu SX, Zhao XQ (2015) Patterns of plant species diversity along an altitudinal gradient and its effect on above-ground biomass in alpine meadows in Qinghai-Tibet Plateau. Biodiversity Science, 23, 451-462. (in Chinese with English abstract) [刘哲, 李 奇, 陈懂懂, 翟文婷, 赵亮, 徐世晓, 赵新全 (2015) 青 藏高原高寒草甸物种多样性的海拔梯度分布格局及对地 上生物量的影响. 生物多样性, 23, 451-462.]

Lü YZ, Li BG (2006) Soil Science. China Agriculture Press,
Beijing. ( in Chinese) [吕贻忠, 李保国 (2006) 土壤学. 中 国农业出版社, 北京.]

Lu XL, Ding SY, You L, Zhang HY (2013) Effects of forest canopy structure on understory vegetation characteristics of Funiu Mountain Nature Reserve. Acta Ecologica Sinica, 33, 4715-4723. (in Chinese with English abstract) [卢训令, 丁 圣彦, 游莉, 张恒月 (2013) 伏牛山自然保护区森林冠层 结构对林下植被特征的影响. 生态学报, 33, 4715-4723.]

Ma KP, Liu YM (1994) Measurement of biotic community diversity. I. $\alpha$ diversity (Part 2). Chinese Biodiversity, 2, 231-239. (in Chinese with English abstract) [马克平, 刘玉 明 (1994) 生物群落多样性的测度方法. I. $\alpha$ 多样性的测 度方法(下). 生物多样性, 2, 231-239.]

Ma M, Zhou X, Du G (2012) Changes in soil seed bank composition after wetland drying up and soil salinization on the Tibetan Plateau. Ecological Engineering, 44, 18-26.

Ma MJ, Baskin CC, Yu KL, Ma Z, Du GZ (2017) Wetland drying indirectly influences plant community and seed bank diversity through soil pH. Ecological Indicators, 80, 186-195.

Matson P, Lohse KA, Hall SJ (2002) The globalization of nitrogen deposition: Consequences for terrestrial ecosystems. Ambio, 31, 113-119.

Ning ZY, Li YL, Yang HL, Zhang ZQ, Zhang JP (2019) Stoichiometry and effects of carbon, nitrogen, and phosphorus in soil of desertified grasslands on community productivity and species diversity. Acta Ecologica Sinica, 39, 3537-3546. (in Chinese with English abstract) [宁志英, 李玉霖, 杨红玲, 张子谦, 张建鹏 (2019) 沙化草地土壤碳氮磷化学计量 特征及其对植被生产力和多样性的影响. 生态学报, 39, 3537-3546.]

Nie YP, Chen HS, Wang KL (2011) Seasonal variation of water sources for plants growing on continuous rock outcrops in limestone area of Southwest China. Chinese Journal of Plant Ecology, 35, 1029-1037. (in Chinese with English abstract) [聂云鹏, 陈洪松, 王克林 (2011) 石灰岩地区连 片出露石丛生境植物水分来源的季节性差异. 植物生态 学报, 35, 1029-1037.]

Ou YD, Su ZY (2012) Dynamics of canopy structure and understory light in montane evergreen broadleaved forest following a natural disturbance in North Guangdong. Acta Ecologica Sinica, 32, 5637-5645. (in Chinese with English abstract) [区余端, 苏志尧 (2012) 粤北山地常绿阔叶林 自然干扰后冠层结构与林下光照动态. 生态学报, 32, 5637-5645.]

Ou ZY, Su ZY, Peng YH, He QF, Huang XR (2013a) Natural regeneration of young Excentrodendron hsienmu in karst mountainous region in Southwest Guangxi, China. Chinese Journal of Applied Ecology, 24, 2440-2446. (in Chinese with English abstract) [欧芷阳, 苏志尧, 彭玉华, 何琴飞, 黄小荣 (2013a) 桂西南喀斯特山地蚬木幼龄植株的天然 更新. 应用生态学报, 24, 2440-2446.]

Ou ZY, Zhu JY, Cao YY, He QF, Huang XR, Peng YH, Pang 
SL (2013b) Coupling relationships between woody plants in Excentrodendron hsienmu community and related edaphic and topographic factors. Chinese Journal of Ecology, 32, 3182-3189. (in Chinese with English abstract) [欧芷阳, 朱 积余, 曹艳云, 何琴飞, 黄小荣, 彭玉华, 庞世龙 (2013b) 蚬木生存群落木本植物与土壤和地形因子的耦 合关系. 生态学杂志, 32, 3182-3189.]

Ou ZY, Zhu JY, Peng YH, He QF, Pang SL (2014) Relationship between plant diversity and environmental factors of Excentrodendron hsienmu community in karst mountains in Pingguo County, Guangxi. Bulletin of Botanical Research, 34, 204-211. (in Chinese with English abstract) [欧芷阳, 朱积余, 彭玉华, 何琴飞, 庞世龙 (2014) 广西平果县喀 斯特山地蚬木生存群落物种多样性与环境的关系. 植物 研究, 34, 204-211.]

Pan YF, Li JF, Huang CY, Liu RH, Jiang Y, Lu ZR, Liang SC (2019) Relationship between plant diversity of shrubs and soil environmental factors along with slope aspects in karst hills of Guilin, Southwest China. Guihaia, 39, 1115-1125. (in Chinese with English abstract) [盘远方, 李娇凤, 黄甫 吟, 刘润红, 姜勇, 陆志任, 梁士楚 (2019) 桂林岩溶石 山不同坡向灌丛植物多样性与土壤环境因子的关系.广 西植物, 39, 1115-1125.]

Peng WX (2009) Study on Patterns of Forest Vegetation and Its Maintenance Mechanism in Karst Peak-Cluster-Depression Region. PhD dissertation, Hunan Agricultural University, Changsha. (in Chinese with English abstract) [彭晚霞 (2009) 喀斯特峰丛洼地森林植被分布格局及其维持机制 研究. 博士学位论文, 湖南农业大学, 长沙.]

Peng Y, Qing FT, Mi K, Xue DY (2015) Study progress on spatial scale effects and coupling relationships of different levels in biodiversity. Acta Ecologica Sinica, 35, 577-583. (in Chinese with English abstract) [彭羽, 卿凤婷, 米凯, 薛达元 (2015) 生物多样性不同层次尺度效应及其耦合 关系研究进展. 生态学报, 35, 577-583.]

Potts MD, Ashton PS, Plotkin JB, Kaufmann LS (2002) Habitat patterns in tropical rainforests: A comparison of 105 plots in Northwest Borneo. Ecology, 83, 2782-2797.

Qiu Y, Zhang JT (2000) The ordination axes clustering based on detrended canonical correspondence analysis ordination and its application to the analysis of the ecological gradients of plant communities. Acta Ecologica Sinica, 20, 199-206. (in Chinese with English abstract) [邱扬, 张金屯 (2000) DCCA排序轴分类及其在关帝山八水沟植物群落生态梯 度分析中的应用. 生态学报, 20, 199-206.]

Shen WH, Ou ZY, Pang SL, He QF, Liang Y (2017) Relationship between the spatial distributions of dominant arbor species and environmental factors of Excentrodendron hsienmu community in Southwest Guangxi, China. Guihaia, 37, 694-701. (in Chinese with English abstract) [申文辉, 欧芷阳, 庞世龙, 何琴飞, 梁艳 (2017) 桂西南蚬木群落 优势树种分布与环境因子的关系. 广西植物, 37, 694-701.]
Shen WH, Tan ZQ, He QF, Peng YH, Zheng W, He F (2016) Species composition and diversity characteristics of Excentrodendron hsienmu-dominated communities in southwestern Guangxi, China. Chinese Journal of Ecology, 35, 1204-1211. (in Chinese with English abstract) [申文辉, 谭 长强, 何琴飞, 彭玉华, 郑威, 何峰 (2016) 桂西南蚬木 优势群落物种组成及多样性特征. 生态学杂志, 35 , 1204-1211.]

Siefert A, Ravenscroft C, Althoff D, Alvarez-Yépiz JC, Carter BE, Glennon KL, Heberling JM, Jo IS, Pontes A, Sauer A, Willis A, Fridley JD (2012) Scale dependence of vegetationenvironment relationships: A meta-analysis of multivariate data. Journal of Vegetation Science, 23, 942-951.

Sohlberg E, Bliss LC (1984) Microscale pattern of vascular plant distribution in two high arctic plant communities. Canadian Journal of Botany, 62, 2033-2042.

Steidinger B (2015) Qualitative differences in tree species distributions along soil chemical gradients give clues to the mechanisms of specialization: Why boron may be the most important soil nutrient at Barro Colorado Island. New Phytologist, 206, 895-899.

Tan HW, Zhou LQ, Xie RL, Huang MF (2006) Study on the potassium characteristic of rendzina soil in the sub-tropical karst of Guangxi. Chinese Journal of Eco-Agriculture, 14, 58-60. (in Chinese with English abstract) [谭宏伟, 周柳强, 谢如林, 黄美福 (2006) 广西亚热带岩溶地区石灰性土 壤钾素特征研究. 中国生态农业学报, 14, 58-60.]

Tan YB, He QF, Zheng W, Peng YH, Hou YR, He F, Shen WH (2016) Effects of canopy structure on understory vegetation in shelterbelt forests along the middle and upper reaches of Pearl River. Chinese Journal of Ecology, 35, 3148-3156. (in Chinese with English abstract) [谭一波, 何琴飞, 郑威, 彭 玉华，侯远瑞，何峰，申文辉 (2016) 珠江流域中上游防 护林冠层结构对林下植被的影响. 生态学杂志, 35, 3148-3156.]

Tian HQ, Chen GS, Zhang C, Melillo JM, Hall CAS (2010) Pattern and variation of $\mathrm{C}: \mathrm{N}$ : P ratios in China's soils: A synthesis of observational data. Biogeochemistry, 98, 139-151.

Wang SL (2012) The Dataset of Observation and Research on Chinese Ecosystem: Forest Ecosystem of Huitong Station, Hunan Province (1960-2006). China Agriculture Press, Beijing. (in Chinese) [汪思龙 (2012) 中国生态系统定位 观测与研究数据集: 森林生态系统卷 (湖南会同站 1960-2006). 中国农业出版社, 北京.]

Wang XH (2010) The Dataset of Observation and Research on Chinese Ecosystem: Forest Ecosystem of Tiantong Station, Zhejiang Province (1983-2009). China Agriculture Press, Beijing. (in Chinese) [王希华 (2010) 中国生态系统定位 观测与研究数据集: 森林生态系统卷 (浙江天童站 1983-2009). 中国农业出版社, 北京.]

Weaver SE, Hamill AS (1985) Effects of soil pH on competitive ability and leaf nutrient content of corn (Zea mays 
L.) and three weed species. Weed Science, 33, 447-451.

Wen L, Song TQ, Du H, Wang KL, Peng WX, Zeng FP, Zeng ZX, He TG (2015) The succession characteristics and its driving mechanism of plant community in karst region, Southwest China. Acta Ecologica Sinica, 35, 5822-5833. (in Chinese with English abstract) [文丽, 宋同清, 杜虎, 王克 林, 彭晚霞, 曾馥平, 曾昭霞, 何铁光 (2015) 中国西南 喀斯特植物群落演替特征及驱动机制. 生态学报, 35, 5822-5833.]

Wright SJ, Yavitt JB, Wurzburger N, Turner BL, Tanner EV, Sayer EJ, Santiago LS, Kaspari M, Hedin LO, Harms KE, Garcia MN, Corre MD (2011) Potassium, phosphorus, or nitrogen limit root allocation, tree growth, or litter production in a lowland tropical forest. Ecology, 92, 1616-1625.

Xiang WS, Nong CG, Wang B, Liu SY, Ding T, He LJ, Li XK, Huang FZ (2013) Growth models of Excentrodendron hsienmu population in a karst seasonal rain forest. Guihaia, 33, 285-290. (in Chinese with English abstract) [向悟生, 农重刚, 王斌, 刘晟源, 丁涛, 何兰军, 李先琨, 黄甫昭 (2013) 喀斯特季节性雨林蚬木种群的增长模型. 广西植 物, 33, 285-290.]

Xie YB, Ma ZP, Yang QS, Fang XF, Zhang ZG, Yan ER, Wang XH (2012) Coexistence mechanisms of evergreen and deciduous trees based on topographic factors in Tiantong region, Zhejiang Province, eastern China. Biodiversity Science, 20, 159-167. (in Chinese with English abstract) [谢 玉彬, 马遵平, 杨庆松, 方晓峰, 张志国, 阎恩荣, 王希 华 (2012) 基于地形因子的天童地区常绿树种和落叶树 种共存机制研究. 生物多样性, 20, 159-167.]

Xu YJ, Lin DM, Shi M, Xie YJ, Wang YZ, Guan ZH, Xiang JY (2017) Spatial heterogeneity and its causes in evergreen broad-leaved forests in the Ailao Mountains, Yunnan Province. Biodiversity Science, 25, 23-33. (in Chinese with English abstract) [徐远杰, 林敦梅, 石明, 谢妍洁, 王逸
之, 管振华, 向建英 (2017) 云南哀牢山常绿阔叶林的空 间分异及其影响因素. 生物多样性, 25, 23-33.]

You YM, Wu XP, Ming AG, Liu T, Chen YK, Zhu HG, Wen YG, Liao SS, Huang XM (2018) Changes of plant functional group in understory and environmental interpretation in the transformation of typical coniferous plantation to native broadleaved species plantation in south subtropical China. Chinese Journal of Ecology, 37, 3194-3201. (in Chinese with English abstract) [尤业明, 吴溪玭, 明安刚, 刘通, 陈 永康, 朱宏光, 温远光, 廖树寿, 黄雪曼 (2018) 南亚热 带典型针叶林改造成乡土阔叶林后林下植物功能群的变 化及其环境解释. 生态学杂志, 37, 3194-3201.]

Yu M, Zhou ZY, Kang FF, Ouyang S, Mi XC, Sun JX (2013) Gradient analysis and environmental interpretation of understory herb-layer communities in Xiaoshegou of Lingkong Mountain, Shanxi, China. Chinese Journal of Plant Ecology, 37, 373-383. (in Chinese with English abstract) [余敏, 周 志勇, 康峰峰, 欧阳帅, 米湘成, 孙建新 (2013) 山西灵 空山小蛇沟林下草本层植物群落梯度分析及环境解释. 植物生态学报, 37, 373-383.]

Yuan TX, Zhang HP, Ou ZY, Tan YB (2014) Effects of topography on the diversity and distribution pattern of ground plants in karst montane forests in Southwest Guangxi, China. Chinese Journal of Applied Ecology, 25, 2803-2810. (in Chinese with English abstract) [袁铁象, 张合平, 欧芷 阳, 谭一波 (2014) 地形对桂西南喀斯特山地森林地表 植物多样性及分布格局的影响. 应用生态学报, 25, 2803-2810.]

Zhang ZH, Hu G, Ni J (2013) Effects of topographical and edaphic factors on the distribution of plant communities in two subtropical karst forests, Southwestern China. Journal of Mountain Science, 10, 95-104.

(责任编委：王希华 责任编辑：黄祥忠) 